\title{
CONTRIBUIÇÕES DE LURIA PARA O TRABALHO COM BEBÊS NA CRECHE
}

José Ricardo Silva

Universidade Estadual Paulista - UNESP, Programa de Pós-Graduação em Educação, Presidente Prudente, SP. E-mail: ricardo.unesp@hotmail.com

\section{RESUMO}

De modo geral, o atendimento dos bebês nas creches pauta-se por características domésticas, improviso e higienista. Entendemos que esta concepção precisa ser superada. Por esta razão, o objetivo deste texto é apresentar alguns indicativos da neuropsicologia de Luria pois acreditamos poder contribuir para o trabalho desenvolvido com bebês nas creches. Na busca por este objetivo, utilizamos como metodologia de pesquisa aquela denominada de bibliográfica. Os resultados apontam sobre a dinamicidade dos componentes cerebrais, para a importância das relações sociais e, principalmente, para uma compreensão do bebê como um ser ativo em suas relações. Por fim, tais indicativos, mudam radicalmente a relação que o professor estabelece com o bebê na creche.

Palavras chaves: Neuropsicologia, Luria, Bebês, creche, desenvolvimento.

\section{LURIA CONTRIBUTIONS TO WORK WITH BABIES IN NURSERY}

\begin{abstract}
Generally, the care of babies in day care is guided by household characteristics, improvisation and hygienist. We understand that this concept needs to be overcome. For this reason, the aim of this paper is to present some indications that we believe we can contribute to the work with babies in nurseries. In pursuit of this goal, we use as a research methodology that called literature. The results point on the dynamics of brain components, the importance of social relations and, particularly, to an understanding of the baby as being active in their relations. Finally, such indicative radically change the relationship that the teacher establishes with the baby in the nursery.
\end{abstract}

Keywords: Neuropsychology, Luria, babies, nursery, development. 


\section{INTRODUÇÃO}

Alexander Romanovich Luria nascido em 16 de julho de 1902 foi um neuropsicólogo soviético especialista em psicologia do desenvolvimento. Ao lado de Vigotski, foi um dos fundadores de psicologia cultural-histórica onde se inclui o estudo das noções de causalidade e pensamento lógico-conceitual da atividade teórica como função do sistema nervoso central. Para este autor, a neurociência possibilita ao pesquisador/professor conhecer as estruturas internas que regem os processos psicológicos e sua dinamicidade.

Para os autores da teoria histórico-cultural, a verdadeira ação promotora do desenvolvimento, deve levar em consideração a situação social de desenvolvimento do indivíduo com o qual se deseja realizar o ato educativo. Vigotski (2006, p. 264) diz que

No início de cada período de idade a relação que se estabelece entre a criança e o entorno que o rodeia, sobretudo o social, é totalmente peculiar, específica, única e irreptível para esta idade. Denominamos essa relação como situação social de desenvolvimento da dita idade. A situação social de desenvolvimento é o ponto de partida para todas as mudanças dinâmicas que se produzem no desenvolvimento durante o período de cada idade.

Por esta razão, para a análise da atividade do bebê, ou seja, o modo como ele entre em relação com a realidade, não podemos perder de vista a situação social de desenvolvimento quando ainda não completaram o seu primeiro ano de vida. De modo geral, os bebês desta faixa etária ao adentrarem à creche, ainda não conhecem grande variedade de objetos e, mais importante, não controlam seus movimentos, logo, não podem operar sobre eles tal como objetos sociais. Por esta razão, sua necessidade psíquica está diretamente relacionada aos adultos e aos objetos que compõem o seu entorno. Dentre estes adultos, queremos aqui destacar o papel dos professores que atuam com bebês em creche.

Contudo, instala-se no trabalho institucionalizado com bebês uma tendência denominada por Martins (2009) como "pedagogia da espera". Esta tendência decorre de uma incoerente percepção do próprio professor acerca de seu trabalho no berçário quando este entende que não há nada a ser feito com os bebês além de prover suas necessidades fisiológicas de alimentação, higiene e sono. Caracterizando, desta forma, a rotina da instituição como afazeres domésticos, focado na proteção, alimentação e higiene, caracterizando o trabalho docente como não diretivo, espontâneo, embasado no cotidiano, no empirismo, no conhecimento tácito e na espera pelo desenvolvimento do bebê que há de vir e que, por isto, não há trabalho pedagógico a ser realizado com ele.

A partir desta problemática, o objetivo deste trabalho é destacar alguns indicativos levantados por Luria. Este autor soviético morreu em 14 de agosto de 1977, mas acreditamos que seus indicativos podem compor e contribuir para as ações dos professores. Nosso intuito com este objetivo é contribuir para a superação da problemática acima citada.

\section{METODOLOGIA}

De delineamento qualitativo, trata-se de uma pesquisa bibliográfica. Este tipo de pesquisa, segundo Macedo (1994), restringe-se na busca por informações bibliográficas, seleção de documentos que se relacionam diretamente com o problema da pesquisa e o respectivo fichamento das referências. Desta forma, apresenta-se como primordial técnica para a elaboração desse presente trabalho a leitura e identificação das informações contidas nos materiais selecionados. Para tanto, elegemos como fontes de pesquisas algumas obras de Luria (1981; 1992; 2010). 


\section{RESULTADOS}

Nos estágios que antecederam e propiciaram o nosso desenvolvimento histórico-social, houve a necessidade de articulação entre mãos, cérebro e linguagem possibilitando ao homem uma relação com a natureza de forma diferente dos outros animais, um modo superior, tornando nosso desenvolvimento essencialmente social. Esta ação do homem sobre a natureza, o trabalho, provocaram dialeticamente uma revolução anatomofisiológico do córtex cerebral. Até hoje, a "ferramenta" que propicia aos seres humanos seu desenvolvimento social, sua humanização, é o sistema nervoso, o mais complexo dentre os seres vivos. É esta cadeia complexa de órgãos e sua plasticidade que nos possibilita desenvolvermos nossa capacidade psíquica. Além disso, este sistema é responsável por todas as reações orgânicas, emocionais e pelas ações guiadas ou não pela consciência. Nas palavras de Luria (2010, p. 196)

[...] a consciência é a habilidade em avaliar as informações sensórias, em responder a elas com pensamentos e ações críticas e em reter traços de memória de forma que traços ou ações passadas possam ser usados no futuro.

Portanto, consciência aqui é entendida como capacidade eminentemente humana que exige relações mentais entre o real e o simbólico, que possibilita a antecipação dos fatos, a criação e a reflexão de ideias de modo a anteceder a ação, pois há o armazenamento, a análise e o planejamento dos atos, das informações de e a partir de imagens psíquicas derivadas de vivências anteriores (LURIA, 2010). Disso podemos afirmar que, há diferenças entre a 'consciência do bebê' e a consciência do adulto, pois esta possibilidade também não está dada biologicamente ao homem.

Para Luria (2010), diferentemente da corrente localizacionista, o cérebro humano e seu psiquismo compõe um sistema complexo que funciona de forma dinâmica. Para ele, o cérebro, a herança biológica decorrente da atividade humana, apresenta três unidades morfofuncionais que orientam o desenvolvimento desde o nascimento: a unidade do tônus do córtex cerebral, a unidade receptora e a unidade efetora. Estas unidades funcionais encontram-se organizadas de forma hierárquica em três zonas corticais: primária, secundária e terciária. É, portanto, todo este aparato biológico que irá orientar o bebê humano em suas primeiras relações com a realidade objetiva.

A unidade responsável pela excitação recebida pelo cérebro do bebê é o córtex. A excitação do córtex cerebral ocorre sob três origens, a saber, processos metabólicos e respiratórios, a chegada do estímulo do mundo exterior, (estes dois comuns a nós e aos animais como reflexo de orientação) e a terceira origem, intensões e planos que se formaram durante a vida social, efetuados com a participação da fala inicialmente externa e depois interna (própria do ser humano) este terceiro tipo de ativação do cérebro se forma ao longo do desenvolvimento. É o córtex que irá proporcionar ao cérebro esta ativação quando em vigília mediante as relações com o meio e o armazenamento dos vestígios destas excitações. Para que os processos mentais sigam o seu curso, o estado ótimo de vigília é essencial. O córtex é responsável, também, pela regulação de processos vegetativos quando o cérebro precisa 'recarregar' e pelos comportamentos inatos e afetivos (LURIA, 2010).

As estruturas que mantém o estado ótimo de vigília do tônus, se situam abaixo do córtex. Estas estruturas desenvolvem uma relação dupla com o córtex: influenciam o tono e são influenciadas pela própria regulação que exercem. Possuem uma estruturação específica para realizarem tal função, uma rede nervosa onde localizam-se neurônios conectados uns aos outros por meio de processos curtos. A excitação proveniente do meio social se espalha gradualmente modificando e modulando pouco a pouco todo o sistema nervoso. Algumas dessas fibras, denominadas de sistema reticular ascendentes, correm para estruturas nervosas superiores 
(tálamo, o núcleo caudado, o arquicórtex e as estruturas do neocórtex) desempenhando papel decisivo na ativação do córtex e na regulação do estado da vigília. Outras fibras de formação reticular, correm em direção oposta, de estruturas superiores (neocórtex, arquicórtex, do núcleo caudado e dos núcleos talâmicos) em direção a estruturas mais baixas (mesencéfalo, hipotálamo e tronco cerebral). Denominadas como sistema reticular descendente, subordinam as referidas estruturas inferiores ao controle exercido por programas que surgem no córtex e que requerem modificação e modulação do estado de vigília para a sua execução (LURIA, 1981).

Essas duas partes da formação reticular constituem, assim, um único sistema funcional verticalmente arranjado, um único aparelho autoregulador construído segundo o princípio do "anel reflexo", capaz de alterar o tono do córtex mas ele próprio também sob influência cortical, sendo regulado e modificado por mudanças que ocorram no córtex e adaptando-se prontamente às condições ambientais e ao curso da atividade. (LURIA, 1981, p. 30)

Esta formação, portanto, contribui para manter o tono cortical e regular o estado funcional do cérebro, ou seja, fator determinante para a vigília. O ser humano, consegue, desta forma, 'selecionar' aquilo que irá direcionar sua atenção ou não. Para Luria (2010) a unidade que irá registrar, processar e conservar na memória os vestígios das experiências vividas é a unidade receptora. Composta por regiões hierárquicas em graus de complexidade, reúne as regiões occipital, temporal, parietal. Há as áreas primárias que são as receptoras dos estímulos, especialização modal que recebe uma determinada modalidade de estímulo (auditivos) occipital (visual) e as parietais (os demais estímulos). A secundária recebe os estímulos, reconhece ou não este estímulo. As regiões terciárias são mais internas e significa socialmente estes estímulos. Entram em ativação, resgatam o que já fora memorizado, agregando toda a experiência do objeto para compreender o que é o instrumento, resgata todos os estímulos que cria condições de relacionamento com este objeto de modo social. Para se tornar mais ativo, em funcionamento complexo, são necessárias mais experiências mediadas pelas palavras que auxiliem na significação do mundo cultural. A significação é propriamente humana, nisto reside a importância da unidade instrumento/signo mediada pela linguagem.

Ao memorizar de forma involuntária e imediata um determinado estímulo externo, é posta em ação uma função psicológica elementar, como quando um ruído desperta a atenção de um cachorro. Mas, quando um signo, por exemplo, um toque, um olhar, o som de uma voz conhecida, possibilita o desenvolvimento da atenção voluntária, uma função psicológica superior essencial está em ação neste momento. Neste caso, a atenção dedicada corresponde a uma possibilidade exclusiva e distinta do homem de exercer controle racional sobre a própria conduta. As funções psicológicas superiores, de característica tipicamente humana, somente são alcançadas quando qualitativamente mediadas nas relações sociais e vividas como atividade pelos sujeitos. Este funcionamento é realizado pela unidade efetora, é ela que programa, regula e controla a atividade intelectual organizada do homem.

\section{DISCUSSÃO}

A primeira semana de vida do bebê, é marcada pela vigília e pelo sono, um estado semisonolento, isolando-se quase que totalmente em relação ao mundo (LURIA, 2010). Passado cerca de 45 dias após o nascimento, período de passividade, transição entre a vida intrauterina e a vida social, desponta no bebê grande interesse pelo mundo a sua volta, inicia-se o chamado período de interesse receptivo. Devido a sua situação social de desenvolvimento, o bebê capta o meio com uma característica sincrética, uma percepção ainda primitiva, um estado caótico, assistemático, desordenado e difuso de percepção com as coisas do mundo exterior mundo, por esta razão, não 
faz diferenciações. Os bebês percebem o mundo de forma desestruturada, não descriminam as partes que formam o todo, por isso, é incapaz de adequar o seu comportamento ao entorno (LURIA, 2010). Serão necessárias ativações de sua atenção e memória involuntária para que, com o passar do tempo, haja registros que possam guia-lo em suas relações.

Esta captação, esta vivência ativa do bebê no meio, é realizada pelos seus órgãos do sentido. Seus órgãos do sentido o guiam em direção às pessoas e, em meses, aos objetos desde que com os devidos estímulos, sob influência de uma cultura sensorial, pois, também, o desenvolvimento destes órgãos do sentido condiciona-se à exposição de estímulos externos e não somente à sua base filogenética. Portanto, recai sobre as sensações o importante papel de iniciarem a captação das primeiras imagens reais como requisito primário na construção do mundo na consciência humana. Condição imprescindível para isso são as influências externas que possibilitarão que tais órgãos recebam e, então, entrem em exercício. São os órgãos dos sentidos, seus analisadores (óticos, acústicos, olfativos, táteis e gustativos), que farão a conexão entre o mundo externo e o interno do bebê já que, desde o nascimento, apresentam alto grau de desenvolvimento (MUKHINA, 1996).

Ao falarmos sobre bebês, devemos levar em conta a multiplicidade de estímulos presente ao seu redor. Devido ao seu nível de desenvolvimento social, tudo é novo, assim, todo o entorno poderia lhe atrair, no entanto, seu organismo consegue filtrar estas informações. No caso dos bebês, esta regulação se torna essencial, haja vista, a multiplicidade de estímulos presente ao seu redor, pois ao passo que ativam, também inibem, afetando igualmente todas as sensações e atos motores. Por esta razão, não podemos considerar que o bebê é um corpo passivo em meio social ou que opere o mundo tal como uma máquina opera ações humanamente programadas, de forma mecânica. Sendo assim, nos referimos ao bebê, como um ser ativo.

Esta conceituação é pertinente pois coloca o bebê em uma situação ativa com e no entorno. Ao entendermos o bebê como ser ativo, o ato educativo com o bebê muda radicalmente, haja vista às tendências biologizantes, assistencialistas e de caráter doméstico citadas anteriormente. Sob esta orientação teórica, o professor precisa entender que o bebê está em relação com o meio, composto por indivíduos que representam determinada cultura, que utilizam objetos culturais e os designam com o auxílio de signos, no entanto, ainda não consegue significálo em sua complexidade. Não cabe, portanto, ao professor desconsiderar a capacidade do bebê de estabelecer relação ativa com o meio mas sim, procurar estabelecer com ele uma interlocução que oriente o seu trabalho e contribua com o desenvolvimento em decurso.

\section{CONCLUSÕES}

Neste sentido, estamos considerando que preceitos da neuropsicologia não podem mais estarem apartadas das discussões educacionais haja vista que partimos de pressupostos psicológicos para estudarmos as práticas pedagógicas que lancem os indivíduos frequentadores da escola em seu desenvolvimento.

Portanto, entendemos que os apontamentos educacionais que emergem a partir da neuropsicologia, constituem-se enquanto saberes necessários para a prática docente. Deste modo, faz-se necessário ampliarmos a discussão na direção dos indicativos básicos da neuropsicologia tomando como ponto de partida Luria para compreendermos o desenvolvimento da consciência humana.

\section{REFERÊNCIAS}

LURIA A. R. Fundamentos de Neuropsicologia. Tradução de Juarez Aranha Ricardo. - Rio de Janeiro: Livros Técnicos e Científicos; São Paulo: Ed. da Universidade de São Paulo, 1981

. A Construção da Mente. São Paulo: Ícone, 1992. 
. O cérebro humano e a atividade consciente. (In) VIGOTSKI L. S., LURIA A. R., LEONTIEV A. N. Linguagem, desenvolvimento e aprendizagem. São Paulo, Ícone Editora, 11a ed., trad. Maria da Pena Villa lobos, 2010.

MACEDO, N. D., Iniciação à pesquisa bibliográfica: guia do estudante para a fundamentação de trabalhos de pesquisa, 2. ed revista, São Paulo: edições Loyola, 1994.

MARTINS L. M. O ensino e o desenvolvimento da criança de zero a três anos. (In) ARCE, A.; MARTINS, L. M. Ensinando aos pequenos: de zero a três anos. Campinas: Alínea, 2009.

MUKHINA V. Psicologia do pré-escolar. São Paulo, Martins Fontes, 1996.

VYGOTSKI, L. S. Obras escogidas. Tomo IV. 2. ed. Madrid: Machado Libros. 2006. 